\title{
Effects of hydroxychloroquine and its metabolites in patients with connective tissue diseases
}

\author{
Duygu Eryavuz Onmaz ${ }^{1}$ (1) $\cdot$ Dilek Tezcan $^{2} \cdot$ Sedat Abusoglu $^{1} \cdot$ Sema Yilmaz $^{2} \cdot$ Fatma Humeyra Yerlikaya $^{1}$. \\ Mustafa Onmaz ${ }^{3}$. Gulsum Abusoglu ${ }^{4}$ Ali Unlu ${ }^{1}$
}

Received: 4 October 2021 / Accepted: 24 October 2021 / Published online: 7 November 2021

(c) The Author(s), under exclusive licence to Springer Nature Switzerland AG 2021

\begin{abstract}
Hydroxychloroquine has attracted attention in the treatment of COVID-19. Many conflicting findings have been reported regarding the efficacy and safety of this drug, which has been used safely in the rheumatological diseases for years. However, these studies lacked measurement methods that allow accurate assessment of hydroxychloroquine and its metabolite levels. The aim of this study was to measure hydroxychloroquine and its metabolite levels in whole blood samples of patients with rheumatoid arthritis (RA), systemic lupus erythematosus (SLE), Sjogren's syndrome (SS) and scleroderma (Scl) by a robust, simple and accurate validated tandem mass spectrometric method, and to investigate the relationship between these levels with drug-related adverse effects and disease activity scores. The validated LC-MS/MS method was applied to measure blood hydroxychloroquine and its metabolite levels of patients with RA, SLE, SS, Scl. Various haematological and biochemical parameters were measured with Beckman-Coulter AU 5800 and Beckman Coulter LH 780 analyzers, respectively. QTc intervals were calculated with Bazett's formula, and the patients were followed up by clinicians in terms of clinical findings and adverse effects. Hydroxychloroquine levels of patients were similar to previous studies. There was a negative correlation between disease activity scores and hydroxychloroquine levels, while the highest correlation was between QTc interval, creatinine and GFR levels with desethylchloroquine. Bidetylchloroquine had the highest correlation with RBC count and liver function tests. Our findings showed that hydroxychloroquine and its metabolite levels were associated with disease activity scores, renal, hepatic function, QTc prolongation, and hematological parameters.
\end{abstract}

Keywords Hydroxychloroquine · Rheumatological diseases · COVID-19 · Adverse effects · QTc prolongation

\section{Introduction}

Coronavirus disease 2019 (COVID-19), caused by severe acute respiratory syndrome coronavirus 2 (SARS-CoV-2), emerged as a new infectious disease in December 2019 (Chen et al. 2020b). To date, Sars-CoV-2 has affected more

Duygu Eryavuz Onmaz

duygu_eryavuz@hotmail.com

1 Department of Biochemistry, Faculty of Medicine, Selcuk University, Alaaddin Keykubat Campus, 42075 Konya, Turkey

2 Division of Rheumatology, Faculty of Medicine, Selcuk University, Konya 42130, Turkey

3 Department of Family Medicine, Faculty of Medicine, Necmettin Erbakan University, Konya, Turkey

4 Department of Medical Laboratory Techniques, Vocational School of Health, Selcuk University, Konya, Turkey than 203 million people in 220 countries and caused more than 4.3 million deaths (Worldometer 2021). Chloroquine and hydroxychloroquine are the most discussed drugs among the repurposing drugs tried as potential therapeutic agents in the treatment of COVID-19. Although initial studies have shown that chloroquine and hydroxychloroquine to be beneficial in the treatment of COVID-19, recent clinical studies lacking critical pharmacology considerations and reliable drug quantifications to ensure optimal dosing and standardization have provided conflicting results (Gautret et al. 2020; Chen et al. 2020a; Kamran et al. 2020; Réa-Neto et al. 2021; Tang et al. 2021). Hydroxychloroquine has antimalarial, anti-inflammatory, immunomodulatory, anti-infective, antitumoral, metabolic and antithrombotic effects. Therefore, it has been used successfully in the treatment of infectious diseases such as HIV, Q fever and rheumatological diseases such as systemic lupus erythematosus, rheumatoid arthritis as well as malaria (White et al. 2020; Nirk et al. 2020). It is 
metabolized mainly by CYP3A4 to active metabolite desethylhydroxychloroquine and inactive metabolites desethylchloroquine and bidesethylchloroquine. It is generally well tolerated by patients, however, it may cause some adverse effects (Morrisette et al. 2020). The most common (up to $50 \%$ ) side effects of hydroxychloroquine are gastrointestinal events such as vomiting, diarrhoea, nausea. Retinopathy is the most common serious side effect associated with highdose and long-term use ( $>5 \mathrm{mg} / \mathrm{kg}$ and $>5$ years). The most serious and life-threatening side effect associated with the use of hydroxychloroquine is QTc prolongation and the risk of ventricular arrhythmia (Juurlink 2020). Hypoglycemia, neuropsychiatric effects, hypersensitivity reactions, abnormal liver functions, drug-drug interactions, hematological effects such as leukopenia, agranulocytosis and thrombocytopenia are other uncommon but serious potential adverse effects related with hydroxychloroquine (Sames et al. 2016; Durcan et al. 2015). Various measurement methods have been developed for the quantitation of hydroxychloroquine levels (Qu et al. 2015; Luo et al. 2020). Liquid chromatography-mass spectrometry (LC-MS/MS) is a major technique in bioanalysis with its high sensitivity, selectivity and accuracy (Jenkins et al. 2015). The aim of this study was to measure hydroxychloroquine and its metabolite levels in whole blood samples from patients with rheumatoid arthritis (RA), systemic lupus erythematosus (SLE), Sjogren's syndrome (SS) and scleroderma (Scl) by a robust, simple and accurate validated tandem mass spectrometric method, and to investigate the relationship between these levels with adverse effects and disease activity scores.

\section{Materials and methods}

\section{LC-MS/MS analysis}

\section{Chemicals and reagents}

Hydroxychloroquine sulfate, carbamazepine, acetonitrile, methanol, HPLC grade water, formic acid were obtained from Sigma Aldrich (St. Louis, MO, USA), desethylhydroxychloroquine and bidesthylchloroquine were obtained from Cayman Chemical (Ann Arbor, MI, USA) and LGS standards (Manchester, NH, USA), respectively.

\section{Sample preparation}

Briefly, $100 \mu \mathrm{L}$ internal standard $(100 \mathrm{ng} / \mathrm{mL}$ carbamazepine) and $600 \mu \mathrm{L}$ acetonitrile were added to $200 \mu \mathrm{L}$ sample or standard solution and vortexed for $30 \mathrm{~s}$. The mixture was centrifuged at $2000 \times g$ for $10 \mathrm{~min}$ and $25 \mu \mathrm{L}$ of supernatant was injected into the LC-MS/MS system.

\section{LC-MS/MS}

Chromatographic analysis was performed by a Shimadzu HPLC system (Kyoto, Japan) and Phenomenex C18 column $(50 \mathrm{~mm} \times 4.6 \mathrm{~mm}, 5 \mu \mathrm{m}, 100 \AA)$. Detection was provided an electrospray ionization API 3200 triple quadrupole mass spectrometer (Applied Biosystems/MDS Sciex). The mobile phase composed of A: $0.1 \%$ formic acid/ water (v/v\%) and B: $0.1 \%$ formic acid/acetonitrile (v/v\%). Total run time was $3 \mathrm{~min}$. The precursor to product ion $\mathrm{m} / \mathrm{z}$ values were $336.2 / 247.2,264.4 / 179.3,308.5 / 179.3$, 292.3/114.45 and 237.0/194.0 for hydroxychloroquine, bidesethylchloroquine, desethylhydroxychloroquine, desethylchloroquine and carbamazepine, respectively.

This is a fully validated method according to the Clinical and Laboratory Standards Institute (CLSI) C62-A: Liquid Chromatography-Mass Spectrometry Methods guidelines and The Food and Drug Administration (FDA) (Wayne 2014; Guidance for Industry, Bionanalytical Method Validation 2018). Intra- and inter-assay imprecision values were less than $10 \%$ and the inter-assay accuracy values ranged between 90.8 and $114.8 \%$ for all analytes. The extraction recoveries ranged between 88.2 and $114.5 \%$ and the matrix effect values were less than $12 \%$ for all analytes.

\section{Patients}

The study included 70 RA (diagnosed according to the 2010 American College of Rheumatology/European League Against Rheumatism (ACR/EULAR) Rheumatoid Arthritis Classification Criteria), 50 SLE (diagnosed according to Systemic Lupus International Collaborating Clinics (SLICC) Classification Criteria), 43 SS (diagnosed according to 2016 ACR/EULAR Classification Criteria for primary Sjögren's Syndrome) and $40 \mathrm{Scl}$ (diagnosed according to 2013 ACR/EULAR Classification Criteria for Scleroderma) patients who applied to the rheumatology outpatient clinic of our hospital and received $400 \mathrm{mg}$ hydroxychloroquine daily (Aletaha et al. 2010; Petri et al. 2012; Shiboski et al. 2017; van den Hoogen et al. 2013).

All patients were older than 18 years and had been prescribed hydroxychloroquine for at least 6 months, without dose modification for 3 months. SLE, RA, SS disease activities were measured by clinicians using the Systemic Lupus Erythematosus Disease Activity Index (SLEDAI), Disease Activity Score 28 (DAS28), and EULAR Sjögren's syndrome disease activity index (ESSDAI), respectively. Exclusion criteria were diabetes mellitus, hypertension or other cardiovascular diseases, thyroid, liver, kidney dysfunction, electrolyte imbalance, use of 
macrolide and quinolone group antibiotics, azole derivative antifungals, antidepressant, antipsychotic, antiarrhythmics, anticonvulsants, antihistaminics and corticosteroids.

The study was approved by the Selcuk University local Ethics Committee (Number: 2020/420, Date: 30/09/2020). Whole blood samples were collected in vacutainer tubes containing EDTA as an anticoagulant within $12 \mathrm{~h}$ after the last dose for measurement of drug and metabolite levels by LC-MS/MS and stored at $-80{ }^{\circ} \mathrm{C}$ until analysis. The hemogram parameters including hemoglobin (HGB), mean corpuscular hemoglobin $(\mathrm{MCH})$, red blood cell count (RBC), mean corpuscular volume (MCV), mean platelet volume (MPV), white blood cell count (WBC), neutrophil (NEU), monocyte (MONO) and lymphocyte (LYM) counts of the patients were analyzed with Beckman Coulter LH 780 analyzer (Beckman Coulter, Miami, FL, USA). For the measurement of biochemistry parameters including creatinine (CRE), aspartate aminotransferase (AST), alanine aminotransferase (ALT), the blood samples collected in serum separator gel tubes and were centrifuged at $2000 \times g$ for $15 \mathrm{~min}$. The serum samples were analyzed with the Beckman-Coulter AU 5800 (Beckman Coulter, Brea, USA) analyzer. Serum C-reactive protein (CRP) levels and erythrocyte sedimentation rate (ESR) were measured by an immunolephelometric method with IMMAGE 800 (Beckman Coulter, Brea, USA) immunochemistry system and by a capillary photometry method with Alifax (Padova, Italy) analyzer. The characteristics of the patients were expressed in Table 1.

\section{Electrocardiography (ECG)}

Standard 12-lead ECGs $(25 \mathrm{~mm} / \mathrm{s}, 10 \mathrm{~mm} / \mathrm{mV})$ were obtained from the patients included in the study at rest. The QT interval was measured as the distance from the beginning of the $\mathrm{Q}$ wave to the end of the $\mathrm{T}$ wave (the point where it reaches the T-P line). Measurements were not made in the leads where the end of the $T$ wave could not be identified. Heart rate corrected QT (QTc) was calculated with Bazett's formula [QT (ms)/ RR (s) ${ }^{1 / 2}$ ] (Bazett 2006).

\section{Data analysis}

Statistical evaluation was carried out using EP Evaluator Release 8 version (Data Innovations, South Burlington, VT), SPSS statistical software package version 21.0, Excel (2010) programs. Data analysis was performed by SCIEX Analyst ${ }^{\circledR}$ 1.6.2 Software. The distribution of data was analyzed with the One-Sample Kolmogorov-Smirnov test. Student's $t$ and Mann-Whitney $U$ tests were used to compare parametric and nonparametric variables, respectively. Kruskal-Wallis test (post-hoc analysis Mann-Whitney $U$ ) and One-Way Anova (post-hoc analysis LSD or Games-Howell) were also performed comparison of multiple groups. Correlations were evaluated by Spearmen's correlation analysis. $p<0.05$ was considered as statistically significant.

\section{Results}

\section{Hydroxychloroquine and metabolite levels}

Whole blood hydroxychloroquine levels of patients with RA, SLE, SS and Scl using $400 \mathrm{mg}$ of hydroxychloroquine daily were 643 (62.8-3300), 806 (61.7-2760), 675 (48.5-3150), and $819(12.1-3770) \mathrm{ng} / \mathrm{mL}$; desethylchloroquine levels were 69.1 (4.6-356.6), 76.4 (4.0-502.0), 57.9 (4.50-465.0), and $74.7(2.0-276.0) \mathrm{ng} / \mathrm{mL}$; bidesethylchloroquine levels were 253 (20.0-1240), 291 (14.0-1477), 250 (18.3-1237), and $255.0(9.96-1018.50) \mathrm{ng} / \mathrm{mL}$; desethylhydroxychloroquine levels were 310 (20.0-2740), 452 (20.0-1700), 324 (19.5-2134.50), and $265(7.2-1053) \mathrm{ng} / \mathrm{mL}$, respectively. When the hydroxychloroquine $(p=0.767)$, desethlychloroquine $(p=0.403)$, bidesethylchloroquine $(p=0.534)$, desethlyhydroxychloroqine $(p=0.167)$, and total metabolite $(p=0.168)$ levels of patients with RA, SLE, SS and Scl were compared, no significant difference was found between the groups in our study. The blood levels of hydroxychloroquine and its metabolites and the ratios of drug-related adverse effects in patients with RA, SLE, SS, and Scl were summarized in Table 2.

\section{The relationship between clinical parameters with hydroxychloroquine and its metabolite}

The median (min-max) values of the QTc intervals of patients with RA, SLE, SS, and Scl were 390 (322-500) ms, 373 (320-459) ms, 390 (295-486) ms, 389 (310-486) $\mathrm{ms}$, respectively. QTc intervals were above $460 \mathrm{~ms}$ in 5.5\% of patients. None of the patients developed retinopathy. Gastrointestinal adverse events including diarrhea, nausea, dyspepsia, abdominal pain, and vomiting were observed in $16 \%$, $8 \%, 5 \%$, and $25 \%$ of patients with RA, SLE, SS, and Scl, respectively. Dermatological side effects including allergic reactions, hyperpigmentation, and pruritis were observed in $2 \%, 4 \%, 5 \%$, and $2.5 \%$ of patients with RA, SLE, SS, and Scl, respectively. Therefore, the most common adverse events in the participants were gastrointestinal side effects with a rate of $14.7 \%$ in the general patient populations.

All participants were divided into two groups according to gastrointestinal side effects: participants observed gastrointestinal side effects (Group 1, $n=30$ ) and nonobserved (Group 2, $n=173$ ) then these groups were compared in terms of whole blood levels of hydroxychloroquine and its metabolites. The blood hydroxychloroquine, desethylchloroquine, bidestylchloroquine, 
Table 1 Clinical, biological and demographic characteristics of the participants

\begin{tabular}{|c|c|c|c|c|}
\hline Parameters & $\mathrm{RA}(n=70)$ & $\operatorname{SLE}(n=50)$ & SS $(n=43)$ & $\operatorname{Scl}(n=40)$ \\
\hline Age (years) & $52.1 \pm 11.9$ & $51.1 \pm 10.5$ & $53.0 \pm 10.2$ & $51.7 \pm 12.1$ \\
\hline Gender $(\mathrm{M} / \mathrm{F})$ & $33 / 37$ & $24 / 26$ & $22 / 21$ & $20 / 20$ \\
\hline BMI $\left(\mathrm{kg} / \mathrm{m}^{2}\right)$ & $27.6 \pm 3.5$ & $27.9 \pm 3.7$ & $27.2 \pm 3.8$ & $27.1 \pm 3.7$ \\
\hline Disease duration (years) & $4.0(0.5-8.0)$ & $4.0(0.5-20)$ & $3.0(1.0-18)$ & $4.0(0.5-9.0)$ \\
\hline \multicolumn{5}{|l|}{ HCQ daily dosing, $n(\%)$} \\
\hline $400 \mathrm{mg}$ & 100 & 100 & 100 & 100 \\
\hline \multicolumn{5}{|l|}{ Disease activity } \\
\hline DAS-28 score for RA & $3.29 \pm 1.21$ & & & \\
\hline SLEDAI score for SLE & & $12.72 \pm 7.93$ & & \\
\hline ESSDAI score for SS & & & $6.30 \pm 3.82$ & \\
\hline $\begin{array}{l}\text { Skin involvement (Generalized/Lim- } \\
\text { ited) for Scl }\end{array}$ & & & & $21 / 19$ \\
\hline \multicolumn{5}{|l|}{ Comedications } \\
\hline Methotrexate $n(\%)$ & 40 & 10 & 11 & 12 \\
\hline Sulfasalazine $n(\%)$ & 60 & 2 & 9 & \\
\hline Leflunomide $n(\%)$ & 17 & 2 & 5 & \\
\hline Etanercept $n(\%)$ & 3 & & & \\
\hline Adalimumab $n(\%)$ & 3 & & & \\
\hline NSAI $n(\%)$ & 10 & 32 & 5 & 28 \\
\hline Colchicine $n(\%)$ & & & & 10 \\
\hline Pentoxifylline $n(\%)$ & & & & 45 \\
\hline Nifedipine $n(\%)$ & & & & 12 \\
\hline Only hydroxychloroquine $n(\%)$ & 23 & 58 & 70 & 43 \\
\hline \multicolumn{5}{|l|}{ Biological characteristics } \\
\hline WBC $\left(10^{9} / \mathrm{L}\right)$ & $7.82 \pm 2.13$ & $6.95 \pm 2.64$ & $6.71 \pm 1.52$ & $7.19 \pm 1.93$ \\
\hline HGB (g/L) & $12.21 \pm 1.50$ & $13.12 \pm 1.64$ & $13.0 \pm 1.21$ & $13.31 \pm 1.22$ \\
\hline $\mathrm{HCT}(\%)$ & $38.0 \pm 3.83$ & $39.94 \pm 4.44$ & $39.58 \pm 3.27$ & $40.60 \pm 3.59$ \\
\hline $\operatorname{PLT}\left(10^{9} / \mathrm{L}\right)$ & $305.48 \pm 87.73$ & $262.71 \pm 73.24$ & $256.46 \pm 62.66$ & $289.28 \pm 78.06$ \\
\hline $\mathrm{RBC}\left(10^{12} / \mathrm{L}\right)$ & $4.56 \pm 0.53$ & $4.65 \pm 0.49$ & $4.60 \pm 0.29$ & $4.76 \pm 0.43$ \\
\hline $\mathrm{MCV}(\mathrm{fL})$ & $84.58 \pm 8.52$ & $86.16 \pm 7.74$ & $86.11 \pm 5.98$ & $85.12 \pm 5.56$ \\
\hline $\mathrm{MCH}(\mathrm{fmol})$ & $27.20 \pm 3.42$ & $33.28 \pm 3.47$ & $28.49 \pm 1.94$ & $27.95 \pm 2.27$ \\
\hline RDW (\%) & $15.40(12.80-27.10)$ & $13.8(12.6-23.90)$ & $13.70(11.90-21.50)$ & $14.05(12.70-19.10)$ \\
\hline PDW $(\%)$ & $16.80(15.80-18.50)$ & $16.60(15.50-18.20)$ & $16.70(15.90-18.0)$ & $16.60(15.50-18.0)$ \\
\hline MPV (fL) & $8.23 \pm 0.83$ & $8.17 \pm 1.11$ & $8.71 \pm 2.12$ & $8.67 \pm 1.01$ \\
\hline $\mathrm{NEU}\left(10^{9} / \mathrm{L}\right)$ & $59.09 \pm 11.14$ & $57.77 \pm 11.73$ & $55.94 \pm 8.49$ & $61.64 \pm 9.13$ \\
\hline $\operatorname{LYM}\left(10^{9} / \mathrm{L}\right)$ & $28.84 \pm 9.19$ & $30.36 \pm 9.75$ & $32.60 \pm 7.73$ & $27.52 \pm 8.22$ \\
\hline MONO & $8.25(3.20-17.10)$ & $8.50(4.40-20.50)$ & $7.60(3.80-12.60)$ & $7.75(4.70-11.90)$ \\
\hline EOS & $2.45(0.10-12.30)$ & $1.90(0.10-5.80)$ & $1.90(0.40-9.0)$ & $2.35(0.20-4.70)$ \\
\hline BASO & $0.50(0.10-2.0)$ & $0.50(0.20-3.10)$ & $0.60(0.20-8.40)$ & $0.60(0.10-1.30)$ \\
\hline ALT (U/L) & $16(8-77)$ & $19(9-58)$ & $15(10-38)$ & $18.5(8-45)$ \\
\hline AST (U/L) & $18(9-55)$ & $21(9-57)$ & $17(11-40)$ & $18.50(8-45)$ \\
\hline CREA (mmol/L) & $0.70(0.44-1.64)$ & $0.71(0.39-1.24)$ & $0.75(0.54-1.13)$ & $0.69(0.44-1.20)$ \\
\hline Estimated GFR, mL/minute & $106.84 \pm 19.82$ & $113.18 \pm 15.37$ & $104.01 \pm 13.52$ & $106.96 \pm 11.36$ \\
\hline NLO & $2.18(0.38-7.21)$ & $2.01(0.21-10.13)$ & $1.76(0.69-3.58)$ & $2.29(1.02-5.92)$ \\
\hline PLO & $10.77(3.28-32.31)$ & $8.54(3.12-25.36)$ & $7.66(4.15-14.51)$ & $10.59(5.52-20.38)$ \\
\hline $\operatorname{ESR}(\mathrm{mm} / \mathrm{h})$ & $23(4.0-94.0)$ & $17.5(2-95)$ & $14(2-52)$ & $14.50(2-62)$ \\
\hline CRP (mg/L) & $7.21(1.76-51.0)$ & $3.84(1.20-38)$ & $3.52(1-13)$ & $3.51(1-58)$ \\
\hline
\end{tabular}


Table 2 Hydroxychloroquine, metabolite levels and drug-related adverse effects

\begin{tabular}{lllll}
\hline & RA $(n=70)$ & SLE $(n=50)$ & SS $(n=43)$ & Scl $(n=40)$ \\
\hline Concentrations & & & & \\
Hydroxychloroquine $(\mathrm{ng} / \mathrm{mL})$ & $643(62.8-3300)$ & $806(61.7-2760)$ & $675(48.5-3150)$ & $819.0(12.1-3770)$ \\
Desethlychloroquine $(\mathrm{ng} / \mathrm{mL})$ & $69.1(4.6-356.6)$ & $76.4(4.0-502.0)$ & $57.9(4.5-465.0)$ & $74.7(2.0-276.0)$ \\
Bidesethlychloroquine $(\mathrm{ng} / \mathrm{mL})$ & $253(20.0-1240)$ & $291(14.0-1477)$ & $250(18.32-1237)$ & $255(9.96-1018)$ \\
Desethylhydroxychloroquine $(\mathrm{ng} / \mathrm{mL})$ & $310(20.0-2740)$ & $452(20.0-1700)$ & $324(19.5-2134)$ & $265(7.2-1053)$ \\
Total metabolite levels $(\mathrm{ng} / \mathrm{mL})$ & $641(44.6-4135)$ & $929(38.0-3529)$ & $687(48.9-2421)$ & $630(18.9-2157)$ \\
Side effects & & & & $389(310-486)$ \\
QTc interval $(\mathrm{ms})$ & $390(322-500)$ & $373(320-459)$ & $390(295-486)$ & 0 \\
Rethinopathy $n(\%)$ & 0 & 0 & 0 & 25 \\
Gastrointestinal events $n(\%)$ & 16 & 8 & 5 & 2.5 \\
Skin reactions $n(\%)$ & 2 & 4 & 5 & \\
\hline
\end{tabular}

desethylhydroxychloroquine and total metabolite levels of Group 1 were 900 (12.1-2450), 95.8 (2.0-390), 326.0 (9.9-1384), 320.0 (7.2-1242) and 811.5 (18.9-3016) ng/ $\mathrm{mL}$, respectively. The blood hydroxychloroquine, desethylchloroquine, bidestylchloroquine, desethylhydroxychloroquine and total metabolite levels of Group 2 were 772 (16.1-3770), 67.4 (4.0-502), 256.0 (14.0-1477), 327 (11.4-2740) and $691.5(19.2-4135) \mathrm{ng} / \mathrm{mL}$, respectively. Whole blood desethylchloroquine $(p=0.024)$ levels of Group 1 were statistically significantly higher than Group 2, while the difference between hydroxychloroquine $(p=0.791)$, bidestylchloroquine $(p=0.356)$, desethylhydroxychloroquine $(p=0.551)$ and total metabolite $(p=0.393)$ levels was not statistically significant.

ECG results of 195 patients were obtained and QTc intervals were calculated with Bazett's formula. The patients were divided into three groups according to their QTc interval: Group 1: 295-360 ms $(n=62)$, Group 2: 360-400 ms $(n=60)$ and Group 3: 400-500 ms $(n=61)$. The whole blood hydroxychloroquine, desethylchloroquine, bidestylchloroquine, desethylhydroxychloroquine and total metabolite levels of Group 1 were 495 (16.1-2760), 34.6 (4.0-354), 137.6 (14.0-1018.5), 230 (11.5-1590), and 450.1 (19.2-1972) $\mathrm{ng} / \mathrm{mL}$, blood levels of Group 2 were 881 (12.1-3770), 84.1 (1.73-361.5), 351.0 (9.9-1237), 410 (7.2-2160), and 955.6 (18.9-3672), blood levels of Group 3 were 800 (61.72-3615), 109.4 (20.12-502), 316.5 (20-1477), 395 (20-2740), and 819.1 (57.02-4135) ng/mL, respectively. The whole blood hydroxychloroquine $(p=0.026)$, desethylchloroquine $(p=0.001)$, bidestylchloroquine $(p=0.001)$, desethylhydroxychloroquine $(p=0.006)$ and total metabolite $(p=0.001)$ levels of Group 2 were statistically significantly higher than Group 1. The blood desethylchloroquine ( $p=0.046$ ) levels of Group 3 were statistically significantly higher than Group 2, while there was no statistically significant difference between hydroxychloroquine $(p=0.602)$, bidestylchloroquine ( $p=0.409)$, desethylhydroxychloroquine $(p=0.204)$ and total metabolite $(p=0.178)$ levels.

Spearmen's correlation analysis showed that there was a positive correlation between blood hydroxychloroquine and its metabolite levels with QTc interval. Correlations between hydroxychloroquine and metabolite levels with QTc interval, disease activity scores and biological parameters were shown in Table 3.

There was a negative correlation between DAS-28 and ESSDAI scores with hydroxychloroquine levels, but no correlation was found between SLEDAI score and drug and metabolite levels. Scl patients were divided into Group 1 (limited involvement, $n=19$ ) and Group 2 (generalized involvement, $n=21$ ) according to skin involvement, and these groups were compared in terms of drug and metabolite levels. The blood hydroxychloroquine [1905 (301.5-3770) vs $512(12.1-3615), p=0.014]$ desethylhydroxychloroquine [387.0 (92.5-1053) vs $187.5(7.2-649), p=0.029]$ and total metabolite [963.1 (167.5-2157) 365.2 (18.9-1788), $p=0.025]$ levels of Group 1 were statistically significantly higher than Group 2, while there was no statistically significant difference between desethylchloroquine [99.0 (20.2-276) vs 63.9 (2.0-228), $p=0.056]$ and bidestylchloroquine [360 (54.7-907) vs 192 (9.9-1018)] levels.

\section{The relationship between biological parameters with hydroxychloroquine and its metabolite concentrations}

Patients were divided into two groups according to their hydroxychloroquine levels as patients with blood hydroxychloroquine levels above $1000 \mathrm{ng} / \mathrm{mL}$ (Group 1, $n=85$ ) and patients with blood hydroxychloroquine levels below $1000 \mathrm{ng} / \mathrm{mL}$ (Group 2, $n=118$ ). RBC [4.53 \pm 0.38 vs $4.89 \pm 0.51, p=0.023], \mathrm{MPV}[8.10 \pm 0.87$ vs $8.60 \pm 0.97$, $p<0.001]$, CRP [3.66 (1-27.60) vs 5.26 (1-58) $p=0.005]$ and GFR [103.78 \pm 17.0 vs $110.88 \pm 19.11, p=0.009]$ levels 
Table 3 The correlations between blood hydroxychloroquine and its metabolite levels with disease activity scores, QTc interval and biological parameters

\begin{tabular}{|c|c|c|c|c|c|c|c|c|c|c|}
\hline \multirow[t]{2}{*}{ Parameters } & \multicolumn{2}{|c|}{ Hydroxychloroquine } & \multicolumn{2}{|c|}{ Desethlychloroquine } & \multicolumn{2}{|c|}{$\begin{array}{l}\text { Bidesethlychloro- } \\
\text { quine }\end{array}$} & \multicolumn{2}{|c|}{$\begin{array}{l}\text { Desethylhydroxy- } \\
\text { chloroquine }\end{array}$} & \multicolumn{2}{|c|}{$\begin{array}{l}\text { Total metabolite } \\
\text { levels }\end{array}$} \\
\hline & $r$ & $p$ & $r$ & $p$ & $r$ & $p$ & $r$ & $p$ & $r$ & $p$ \\
\hline QTc interval (ms) & 0.224 & 0.002 & 0.389 & $<0.001$ & 0.34 & $<0.001$ & 0.307 & $<0.001$ & 0.351 & $<0.001$ \\
\hline DAS-28 score for RA & -0.258 & 0.031 & -0.075 & 0.539 & -0.071 & 0.558 & -0.056 & 0.643 & -0.083 & 0.497 \\
\hline SLEDAI score for SLE & -0.262 & 0.066 & 0.002 & 0.99 & -0.21 & 0.143 & -0.161 & 0.264 & -0.170 & 0.238 \\
\hline ESSDAI score for SS & -0.416 & 0.005 & -0.173 & 0.268 & -0.046 & 0.77 & -0.126 & 0.421 & -0.078 & 0.62 \\
\hline WBC $\left(10^{9} / \mathrm{L}\right)$ & 0.073 & 0.315 & 0.029 & 0.695 & -0.021 & 0.777 & 0.026 & 0.727 & 0.010 & 0.892 \\
\hline HGB (g/L) & 0.104 & 0.154 & 0.091 & 0.211 & -0.05 & 0.497 & -0.051 & 0.488 & -0.033 & 0.656 \\
\hline HCT (L/L) & 0.067 & 0.355 & 0.066 & 0.369 & -0.068 & 0.356 & -0.067 & 0.357 & -0.053 & 0.471 \\
\hline $\operatorname{PLT}\left(10^{9} / \mathrm{L}\right)$ & 0.026 & 0.719 & -0.052 & 0.475 & -0.01 & 0.892 & -0.006 & 0.939 & -0.009 & 0.902 \\
\hline $\mathrm{RBC}\left(10^{12} / \mathrm{L}\right)$ & -0.181 & 0.012 & -0.306 & $<0.001$ & -0.318 & $<0.001$ & -0.312 & $<0.001$ & -0.330 & $<0.001$ \\
\hline MCV (fL) & 0.116 & 0.112 & 0.258 & $<0.001$ & 0.157 & 0.031 & 0.128 & 0.079 & 0.171 & 0.018 \\
\hline $\mathrm{MCH}$ (fmol) & 0.114 & 0.118 & 0.269 & $<0.001$ & 0.164 & 0.024 & 0.131 & 0.073 & 0.178 & 0.014 \\
\hline RDW (\%) & -0.117 & 0.107 & -0.181 & 0.013 & -0.129 & 0.077 & -0.127 & 0.081 & -0.146 & 0.045 \\
\hline PDW (\%) & 0.004 & 0.954 & 0.049 & 0.503 & 0.059 & 0.417 & 0.042 & 0.569 & 0.053 & 0.465 \\
\hline MPV (fL) & -0.230 & 0.001 & -0.107 & 0.141 & -0.072 & 0.323 & -0.179 & 0.013 & -0.141 & 0.052 \\
\hline $\operatorname{NEU}\left(10^{9} / \mathrm{L}\right)$ & 0.052 & 0.473 & 0.036 & 0.625 & 0.007 & 0.925 & -0.03 & 0.686 & 0.005 & 0.95 \\
\hline LYM $\left(10^{9} / \mathrm{L}\right)$ & -0.047 & 0.517 & -0.043 & 0.558 & -0.025 & 0.735 & 0.008 & 0.910 & -0.023 & 0.758 \\
\hline MONO & -0.100 & 0.172 & -0.021 & 0.779 & -0.018 & 0.807 & -0.039 & 0.596 & -0.033 & 0.647 \\
\hline EOS & 0.006 & 0.931 & 0.029 & 0.691 & 0.118 & 0.107 & 0.098 & 0.179 & 0.089 & 0.224 \\
\hline BASO & -0.019 & 0.794 & -0.006 & 0.939 & 0.068 & 0.349 & -0.037 & 0.617 & 0.005 & 0.946 \\
\hline $\operatorname{ALT}(\mathrm{U} / \mathrm{L})$ & 0.073 & 0.315 & 0.078 & 0.285 & 0.188 & 0.01 & 0.123 & 0.092 & 0.133 & 0.067 \\
\hline $\operatorname{AST}(\mathrm{U} / \mathrm{L})$ & 0.213 & 0.003 & 0.236 & 0.001 & 0.397 & $<0.001$ & 0.328 & $<0.001$ & $\mathbf{0 . 3 3 7}$ & $<0.001$ \\
\hline CREA (mmol/L) & 0.208 & 0.004 & 0.32 & $<0.001$ & 0.218 & 0.003 & 0.137 & 0.060 & 0.203 & 0.005 \\
\hline Estimated GFR, mL/minute & -0.268 & $<0.001$ & -0.321 & $<0.001$ & -0.232 & 0.001 & -0.167 & 0.022 & -0.202 & 0.005 \\
\hline NLO & 0.049 & 0.498 & 0.027 & 0.708 & 0.018 & 0.8 & -0.017 & 0.813 & 0.01 & 0.887 \\
\hline PLO & 0.061 & 0.399 & 0.03 & 0.705 & 0.017 & 0.813 & 0.02 & 0.781 & 0.027 & 0.709 \\
\hline $\mathrm{ESR}(\mathrm{mm} / \mathrm{h})$ & -0.144 & 0.047 & -0.125 & 0.085 & -0.036 & 0.621 & -0.082 & 0.258 & -0.077 & 0.289 \\
\hline $\mathrm{CRP}(\mathrm{mg} / \mathrm{L})$ & -0.299 & $<0.001$ & -0.264 & $<0.001$ & -0.266 & $<0.001$ & -0.234 & 0.001 & -0.277 & $<0.001$ \\
\hline
\end{tabular}

Bold values represent statistically significant correlations

of Group 1 were significantly lower than Group 2, while AST [21 (9-55) vs 18 (8-57), $p=0.012]$ levels were higher.

Spearmen's correlation analysis showed a negative correlation between hydroxychloroquine levels and MPV, RBC, GFR, ESR, and CRP levels, while a positive correlation between AST and creatinine levels (Table 3).

\section{Discussion}

The SARS-CoV-2 virus is life-threatening in severely affected patients by causing immune dysregulation, cytokine storm, and multi-organ failure. Until now, an effective treatment for the disease has not been developed yet (Song et al. 2020). However, to quickly prevent the spread, morbidity and mortality of COVID-19, the repurposing of various drugs has been adopted and many trials have been conducted
(Martinez 2021). Hydroxychloroquine has been one of these drugs. Several clinical trials and in vitro studies have reported promising results in the early stages regarding the role of hydroxychloroquine in the treatment of COVID-19, while subsequent observational studies and clinical trials have reported no effect of hydroxychloroquine (Gautret et al. 2020; Chen et al. 2020a; Kamran et al. 2020; Réa-Neto et al. 2021; Tang et al. 2021). The open-label Randomized Evaluation of COVID-19 Therapy (RECOVERY) trial in the United Kingdom announced the early closure of the hydroxychloroquine arm after finding that among patients hospitalized with COVID-19 who received hydroxychloroquine did not have lower mortality rates at 28th day compared to those who received usual care. In addition, the results demonstrated that the patients who received hydroxychloroquine had a longer duration of hospitalization and, among those who were not undergoing mechanical ventilation at baseline, 
a higher risk of invasive mechanical ventilation or death than those who received usual care. Hydroxychloroquine has been proposed as a treatment for COVID-19 largely on the basis of its in vitro SARS-CoV-2 antiviral activity and on data from observational studies reporting an effective reduction in viral loads. However, the 4-aminoquinoline drugs are relatively weak antiviral agents. The demonstration of therapeutic efficacy of hydroxychloroquine in severe COVID-19 would require rapid attainment of efficacious levels of free drug in the blood and respiratory epithelium. These levels were predicted to be at the upper end of those observed during steady-state treatment of rheumatoid arthritis with hydroxychloroquine. The primary concern with short-term, high-dose 4-aminoquinoline regimens is cardiovascular toxicity. Hydroxychloroquine causes predictable prolongation of the corrected QTc interval on electrocardiography, which is exacerbated by coadministration with azithromycin, as widely prescribed in COVID-19 treatment. Therefore, in the RECOVERY trial, the efficacy of hydroxychloroquine was found to be limited due to its relatively weak antiviral effect, the need to rapidly reach effective concentrations in the blood and respiratory epithelium to exert its therapeutic effect, and consequently the increased risk of adverse effects of hydroxychloroquine (Horby et al. 2020). Similarly, in subsequent clinical trials, it was reported that the use of hydroxychloroquine did not improve the clinical situation, moreover, it increased the risk of adverse effects such as QTc prolongation, cardiac arrhythmia, renal dysfunction and the risk of mechanical ventilation (Mercuro et al. 2020; Hooks et al. 2020). However, one of the major shortcomings of these studies is the lack of validated methods for measuring blood levels of drugs and their metabolites, and the lack of comprehensive evaluation of the relationships between these levels and clinical parameters. Although a few studies in SLE, RA patients have shown that hydroxychloroquine as well as its metabolites have significant effects on treatment efficacy and adverse effects, there is no comprehensive study on this subject (Jallouli et al. 2015b; Omri et al. 2020; Blanchet et al. 2020; Carlsson et al. 2020; Munster et al. 2002).

This is the first comprehensive study for the measurement of hydroxychloroquine and metabolite levels by the validated tandem mass spectrometric method in patients with RA, SLE, SS, and Scl, and investigating the relationship between these concentrations with disease activity scores, adverse effects, and various biological parameters. Firstly, the validated method was applied for the measurement of whole blood hydroxychloroquine and its three metabolites in patients with RA, SLE, SS and Scl. Jallouli et al. reported whole blood hydroxychloroquine levels as 917 (range 208-3316) $\mathrm{ng} / \mathrm{mL}$ for 509 SLE patients receiving $400 \mathrm{mg}$ /day (Jallouli et al. 2015b9. El Omri et al. reported median whole blood hydroxychloroquine levels as $830 \mathrm{ng} /$ $\mathrm{mL}$ (range 35-3200 $\mathrm{ng} / \mathrm{mL}$ ) for 80 Moroccan SLE patients receiving $400 \mathrm{mg}$ of hydroxychloroquine daily (Omri et al. $2020)$. Blanchet et al. reported the mean $( \pm$ SD) whole blood hydroxychloroquine levels as $916 \pm 449 \mathrm{ng} / \mathrm{mL}$ for $573 \mathrm{SLE}$ patients (Blanchet et al. 2020). Hydroxychloroquine levels have been measured majorly in patients with SLE up to date. Hydroxychloroquine blood levels may vary between patients despite the same dosing regimen. Studies have reported that body mass index, corticosteroid intervention, glomerular filtration rate, nonadherence to treatment and possible genetic variations affect hydroxychloroquine levels. However, it has been reported that ethnicity, smoking, drug-drug interaction with antacids or with inhibitors or inducers of cytochrome P450 enzymes have no effect on hydroxychloroquine levels (Jallouli et al. 2015b; Omri et al. 2020; Blanchet et al. 2020; Carlsson et al. 2020). We measured the levels of hydroxychloroquine and its metabolites in patients with SS, Scl and RA in addition to patients with SLE and our results were consistent with previous studies (Table 2).

The second important aspect of the study was to investigate the relationship between hydroxychloroquine and its metabolite levels measured by a robust, reliable, validated tandem mass spectrometric method, and drug-related adverse effects, disease activity scores. The role of metabolites in the efficacy and toxicity of hydroxychloroquine therapy is not yet fully understood. Desethylhydroxychloroquine is thought to be the only active metabolite of hydroxychloroquine. However, gastrointestinal side effects and ocular toxicity were reported to be associated with blood hydroxychloroquine and bidestylchloroquine levels in patients with rheumatoid arthritis, while clinical improvement was reported to be associated with blood desethylhydroxychloroquine levels (Munster et al. 2002). Our findings showed that there is a relationship between gastrointestinal side effects and blood desethylchloroquine levels. Blood desethylchloroquine levels of participants with gastrointestinal side effects were found to be higher than patients without gastrointestinal symptoms. The highest correlation with QTc interval was desethylchloroquine. The patients were divided into three groups according to their QTc interval: Group 1: 295-360 ms $(n=62)$, Group 2: 360-400 $\mathrm{ms}(n=60)$ and Group 3: $400-500 \mathrm{~ms}(n=61)$. The blood hydroxychloroquine and its metabolite levels of Group 2 were statistically significantly higher than Group 1 . The desethylchloroquine levels of Group 3 were statistically significantly higher than Group 2. Therefore, there was a significant relationship between QTc interval and especially blood desethylchloroquine levels. Correlations between disease activity scores with hydroxychloroquine and metabolite levels showed a negative correlation between hydroxychloroquine levels with DAS-28 and ESSDAI scores. The hydroxychloroquine and desethylhydroxychloroquine levels of patients with limited skin involvement were found to be higher than patients with generalized involvement in scleroderma (Table 3). 
Therefore, it was considered that the parent drug may be more effective in reducing disease activity. One of the characteristics of rheumatological diseases is inflammation. The inflammatory response contributes to the elimination of pathogens and tissue regeneration. These changes are associated with an increase in the levels of markers such as ESR, CRP. Although these markers are not specific, they are commonly used by clinicians to monitor disease activity in rheumatologic diseases (Yap et al. 2018). Various studies have shown that hydroxychloroquine reduces CRP and ESR levels, while there are studies showing that the use of hydroxychloroquine does not have a significant effect on CRP and ESR levels (Shapiro and Levy 2017; Tishler et al. 1999; Morris et al. 2011). Our findings showed that there was a negative correlation between CRP levels with hydroxychloroquine and metabolite levels, while a negative correlation was found between ESR and hydroxychloroquine levels (Table 3). Therefore, hydroxychloroquine and its metabolites considered to be effective in regressing disease activity by limiting inflammation.

Another important aspect of our study was the investigation of the relationship between various biological parameters with hydroxychloroquine and metabolite levels. Patients were divided into 2 groups according to their hydroxychloroquine levels as patients with blood hydroxychloroquine levels above $1000 \mathrm{ng} / \mathrm{mL}$ (Group1, $n=85$ ) and patients with blood hydroxychloroquine levels below $1000 \mathrm{ng} / \mathrm{mL}$ (Group $2, n=118$ ) and these groups were compared in terms of biological parameters. Various studies reported that the use of hydroxychloroquine is associated with a lower incidence of chronic kidney disease (CKD) and delays renal damage (Wu et al. 2018; Pons-Estel et al. 2009), while Wu et al. reported that hydroxychloroquine has a neutral effect on CKD risk in patients with SLE and Jallouli et al. reported that the median blood levels of hydroxychloroquine were higher in the SLE patients with chronic renal failure than the SLE patients with normal renal function (Jallouli et al. 2015b; Wu et al. 2020). Our findings showed that the levels of hydroxychloroquine and its three metabolites were positively correlated with creatinine levels, and a negative correlated with GFR. The highest correlation between GFR and creatinine levels was between desethylchloroquine levels (Table 3). However, there was no statistically significant difference between the creatinine levels of Group 1 and Group 2, while the GFR levels of Group 1 were slightly lower than Group 2. Therefore, our findings suggest that blood hydroxychloroquine and metabolite levels have an effect on renal function, but there is no risk of serious renal toxicity at therapeutic levels.

In addition, RBC and MPV levels of Group 1 were statistically significantly lower than Group 2. However, RBC and MPV levels were within the reference range in both groups. Correlation analysis yielded a negative correlation between RBC levels with hydroxychloroquine and its three metabolites, and a negative correlation between MPV and hydroxychloroquine levels (Table 3). As a result of our literature search, we could not reach any study investigating the effect of hydroxychloroquine on hematological parameters. However, it has been reported that hydroxychloroquine rarely causes hematological side effects. Our findings show that there is a relationship between low RBC levels with increased hydroxychloroquine and metabolite levels. However, it is considered that the effect of hydroxychloroquine on hematological parameters at therapeutic levels was limited.

Liver injury induced by hydroxychloroquine is a very rarely reported side effect (Tang et al. 2012). There are some case reports reporting liver injury with high AST, ALT, bilirubin levels due to the use of hydroxychloroquine, but these cases are rare. Our findings showed that AST levels of Group 1 were slightly higher than Group 2, while there was no significant difference between ALT levels. Correlation analysis showed a positive correlation between AST levels and hydroxychloroquine and its metabolites levels, however, the highest correlation was between AST and bidestylchloroquine levels. Morever, there was a positive correlation between ALT levels and bidesethylchloroquine levels (Table 3). Although our findings show that especially bidestylchloroquine may be effective on hepatic function, the possibility of hepatotoxicity due to the use of hydroxychloroquine in the specified concentrations seems low.

\section{Conclusion}

The developed validated tandem mass spectrometric method has been successfully applied for the measurement of blood hydroxychloroquine and metabolite levels in patients with SLE, RA, SS and Scl, and these levels were found to be compatible with the reported levels. Moreover, the association of hydroxychloroquine and metabolite levels with clinical parameters was investigated. Our findings revealed a relationship between hydroxychloroquine and desethylhydroxychloroquine levels on the limitation of inflammation and disease activity. Especially, bidestylchloroquine appeared to be associated with liver function, desethylchloroquine appeared to be associated with QTc prolongation, renal function, and gastrointestinal adverse effects. Our findings suggest that at therapeutic levels, hydroxychloroquine or its metabolites do not cause serious adverse effects in patients with rheumatologic disease. However, blood hydroxychloroquine and its metabolite levels are associated with disease activity, inflammation, hematological parameters, hepatic and renal function. Depending on pharmacokinetic variability, decreases in hydroxychloroquine or metabolite levels seem to be associated with decreased treatment efficacy, and increased blood levels seem to be associated with an 
increased risk of adverse effects. Therefore, monitoring of hydroxychloroquine blood levels is important to provide an effective and safe treatment.

Author contributions All authors contributed to the design of the study, interpretation of the results, writing, and validation.

Funding The interpretation and conclusions in this study are the authors' view, and the funders had no role in study design, data analysis, interpretation of results or report writing.

Data availability All the data regarding findings of the study has been added to the manuscript.

\section{Declarations}

Conflict of interest The authors declare that they have no conflict of interest relevant to the content of this manuscript.

Ethics approval The study was approved by the Selcuk University local Ethics Committee (Number: 2020/420, Date: 30/09/2020).

Consent to participate Informed consent of all patients was obtained.

\section{References}

Aletaha D, Neogi T, Silman AJ, Funovits J, Felson DT, Bingham CO 3rd, Birnbaum NS, Burmester GR, Bykerk VP, Cohen MD, Combe B, Costenbader KH, Dougados M, Emery P, Ferraccioli G, Hazes JM, Hobbs K, Huizinga TW, Kavanaugh A, Kay J, Kvien TK, Laing T, Mease P, Ménard HA, Moreland LW, Naden RL, Pincus T, Smolen JS, Stanislawska-Biernat E, Symmons D, Tak PP, Upchurch KS, Vencovský J, Wolfe F, Hawker G (2010) 2010 Rheumatoid arthritis classification criteria: an American college of rheumatology/European league against rheumatism collaborative initiative. Arthritis Rheum 62(9):2569-2581. https://doi.org/ $10.1002 /$ art. 27584

Bazett H (2006) An analysis of the time relationships of electrocardiograms. Ann Noninvasive Electrocardiol 2:177-194. https://doi. org/10.1111/j.1542-474X.1997.tb00325.x

Blanchet B, Jallouli M, Allard M, Ghillani-Dalbin P, Galicier L, Aumaître O, Chasset F, Le Guern V, Lioté F, Smail A, Limal N, Perard L, Desmurs-Clavel H, Le Thi HD, Asli B, Kahn J-E, Sailler L, Ackermann F, Papo T, Sacré K, Fain O, Stirnemann J, Cacoub P, Leroux G, Cohen-Bittan J, Sellam J, Mariette X, Goulvestre C, Hulot JS, Amoura Z, Vidal M, Piette J-C, Astudillo L, Belizna C, Belmatoug N, Benveniste O, Benyamine A, Bezanahary $\mathrm{H}$, Blanco $\mathrm{P}$, Bodaghi $\mathrm{B}$, Bourgeois $\mathrm{P}$, Brihaye $\mathrm{B}$, Chatelus E, Damade R, Daugas E, De Gennes C, Delfraissy J-F, Delluc C, Delluc A, Duhaut P, Dupuy A, Durieu I, Ea HK, Farge D, FunckBrentano C, Gandjbakhch F, Gellen-Dautremer J, Godeau B, Goujard C, Grandpeix C, Grange C, Grimaldi L, Guettrot-Imbert G, Guillevin L, Hachulla E, Harle J-R, Haroche J, Hausfater P, Jouquan J, Kaplanski G, Keshtmand H, Khellaf M, Lambotte O, Launay D, Lechat P, Levesque H, Lidove O, Liozon E, Ly K, Mahevas M, Mariampillai K, Mathian A, Mazodier K, Michel M, Morel N, Mouthon L, Musset L, Ngack R, Ninet J, Oksenhendler E, Pellegrin J-L, Peyr O, Piette A-M, Poindron V, Pourrat J, Roux F, Saadoun D, Sahali S, Saint-Marcoux B, Sarrot-Reynauld F, Schoindre Y, Sene D, Serratrice J, Seve P, Sibilia J, Simon C,
Sordet C, Terrier B, Trad S, Viallard J-F, Vidal E, Wechsler B, Weiller P-J, Jourde-Chiche N, Costedoat-Chalumeau N (2020) Hydroxychloroquine levels in patients with systemic lupus erythematosus: whole blood is preferable but serum levels also detect non-adherence. Arthritis Res Ther 22(1):223. https://doi.org/10. 1186/s13075-020-02291-z

Carlsson H, Hjorton K, Abujrais S, Rönnblom L, Åkerfeldt T, Kultima K (2020) Measurement of hydroxychloroquine in blood from SLE patients using LC-HRMS-evaluation of whole blood, plasma, and serum as sample matrices. Arthritis Res Ther 22(1):125. https://doi.org/10.1186/s13075-020-02211-1

Chen J, Liu D, Liu L, Liu P, Xu Q, Xia L, Ling Y, Huang D, Song S, Zhang D, Qian Z, Li T, Shen Y, Lu H (2020a) A pilot study of hydroxychloroquine in treatment of patients with moderate COVID-19. Zhejiang Da Xue Xue Bao Yi Xue Ban 49(2):215219. https://doi.org/10.3785/j.issn.1008-9292.2020.03.03

Chen Z, Ding S, Wang YP, Chen L, Mao JY, Yang Y, Sun JT, Yang K (2020b) Association of carbamylated high-density lipoprotein with coronary artery disease in type 2 diabetes mellitus: carbamylated high-density lipoprotein of patients promotes monocyte adhesion. J Transl Med 18(1):460. https://doi.org/ 10.1186/s12967-020-02623-2

Durcan L, Clarke WA, Magder LS, Petri M (2015) Hydroxychloroquine blood levels in systemic lupus erythematosus: clarifying dosing controversies and improving adherence. J Rheumatol 42(11):2092-2097. https://doi.org/10.3899/jrheum.150379

Gautret P, Lagier J-C, Parola P, Hoang VT, Meddeb L, Mailhe M, Doudier B, Courjon J, Giordanengo V, Vieira VE, Tissot Dupont $\mathrm{H}$, Honoré $\mathrm{S}$, Colson $\mathrm{P}$, Chabrière E, La Scola $\mathrm{B}$, Rolain J-M, Brouqui P, Raoult D (2020) Hydroxychloroquine and azithromycin as a treatment of COVID-19: results of an openlabel non-randomized clinical trial. Int J Antimicrob Agents 56(1):105949-105949. https://doi.org/10.1016/j.ijantimicag. 2020.105949

Guidance for Industry, Bionanalytical Method Validation (2018) US Department of Health and Human Services/Food and Drug Administration Centre for Drug Evaluation and Research (CDER)/ Centre for Veterinary Medicine (CVM)

Hooks M, Bart B, Vardeny O, Westanmo A, Adabag S (2020) Effects of hydroxychloroquine treatment on QT interval. Heart Rhythm 17(11):1930-1935. https://doi.org/10.1016/j.hrthm.2020.06.029

Horby P, Mafham M, Linsell L, Bell JL, Staplin N, Emberson JR, Wiselka M, Ustianowski A, Elmahi E, Prudon B, Whitehouse T, Felton T, Williams J, Faccenda J, Underwood J, Baillie JK, Chappell LC, Faust SN, Jaki T, Jeffery K, Lim WS, Montgomery A, Rowan K, Tarning J, Watson JA, White NJ, Juszczak E, Haynes R, Landray MJ (2020) Effect of hydroxychloroquine in hospitalized patients with Covid-19. N Engl J Med 383(21):2030-2040. https://doi.org/10.1056/NEJMoa2022926

Jallouli M, Galicier L, Zahr N, Aumaître O, Francès C, Le Guern V, Lioté F, Smail A, Limal N, Perard L, Desmurs-Clavel H, Le Thi HD, Asli B, Kahn JE, Pourrat J, Sailler L, Ackermann F, Papo T, Sacré K, Fain O, Stirnemann J, Cacoub P, Leroux G, CohenBittan J, Sellam J, Mariette X, Blanchet B, Hulot JS, Amoura Z, Piette JC, Costedoat-Chalumeau N (2015a) Determinants of hydroxychloroquine blood concentration variations in systemic lupus erythematosus. Arthritis Rheumatol 67(8):2176-2184. https://doi.org/10.1002/art.39194

Jallouli M, Galicier L, Zahr N, Aumaître O, Francès C, Le Guern V, Lioté F, Smail A, Limal N, Perard L, Desmurs-Clavel H, Le Thi HD, Asli B, Kahn JE, Pourrat J, Sailler L, Ackermann F, Papo T, Sacré K, Fain O, Stirnemann J, Cacoub P, Leroux G, Cohen-Bittan J, Sellam J, Mariette X, Blanchet B, Hulot JS, Amoura Z, Piette JC, Costedoat-Chalumeau N, Plaquenil Lupus Systemic Study G (2015b) Determinants of hydroxychloroquine blood concentration 
variations in systemic lupus erythematosus. Arthritis Rheumatol 67:2176-2184. https://doi.org/10.1002/art.39194

Jenkins R, Duggan JX, Aubry AF, Zeng J, Lee JW, Cojocaru L, Dufield D, Garofolo F, Kaur S, Schultz GA, Xu K, Yang Z, Yu J, Zhang YJ, Vazvaei F (2015) Recommendations for validation of LC-MS/ MS bioanalytical methods for protein biotherapeutics. AAPS J 17(1):1-16. https://doi.org/10.1208/s12248-014-9685-5

Juurlink DN (2020) Safety considerations with chloroquine, hydroxychloroquine and azithromycin in the management of SARS-CoV-2 infection. Can Med Assoc J 192(17):E450. https://doi.org/10. 1503/cmaj.200528

Kamran SM, Z-e-H M, Naseem A, Azam R, Ullah N, Saeed F, Alamgir W, Saleem S, Nisar S, Hussain M (2020) Clearing the fog: is hydroxychloroquine effective in reducing corona virus disease-2019 progression: a randomized controlled trial. MedRxiv. https://doi.org/10.1101/2020.07.30.20165365

Luo X, Peng Y, Ge W (2020) A sensitive and optimized HPLC-FLD method for the simultaneous quantification of hydroxychloroquine and its two metabolites in blood of systemic lupus erythematosus patients. J Chromatogr Sci 58(7):600-605. https://doi.org/10. 1093/chromsci/bmaa023

Martinez MA (2021) Lack of effectiveness of repurposed drugs for covid-19 treatment. Front Immunol. https://doi.org/10.3389/ fimmu.2021.635371

Mercuro NJ, Yen CF, Shim DJ, Maher TR, McCoy CM, Zimetbaum PJ, Gold HS (2020) Risk of QT interval prolongation associated with use of hydroxychloroquine with or without concomitant azithromycin among hospitalized patients testing positive for coronavirus disease 2019 (COVID-19). JAMA Cardiol 5(9):1036-1041. https://doi.org/10.1001/jamacardio.2020.1834

Morris SJ, Wasko MC, Antohe JL, Sartorius JA, Kirchner HL, Dancea S, Bili A (2011) Hydroxychloroquine use associated with improvement in lipid profiles in rheumatoid arthritis patients. Arthritis Care Res (hoboken) 63(4):530-534. https://doi.org/10. 1002/acr.20393

Morrisette T, Lodise T, Scheetz M, Goswami S, Pogue J, Rybak M (2020) The pharmacokinetic and pharmacodynamic properties of hydroxychloroquine and dose selection for COVID-19: putting the cart before the horse. Infect Dis Ther. https://doi.org/10.1007/ s40121-020-00325-2

Munster T, Gibbs JP, Shen D, Baethge BA, Botstein GR, Caldwell J, Dietz F, Ettlinger R, Golden HE, Lindsley H, McLaughlin GE, Moreland LW, Roberts WN, Rooney TW, Rothschild B, Sack M, Sebba AI, Weisman M, Welch KE, Yocum D, Furst DE (2002) Hydroxychloroquine concentration-response relationships in patients with rheumatoid arthritis. Arthritis Rheum 46(6):1460 1469. https://doi.org/10.1002/art.10307

Nirk EL, Reggiori F, Mauthe M (2020) Hydroxychloroquine in rheumatic autoimmune disorders and beyond. EMBO Mol Med 12(8):e12476. https://doi.org/10.15252/emmm.202012476

Omri N, Mekouar F, Assoufi N, Maaroufi A, Charef A, Smaali J, Jira M, Fatihi J, Eljaoudi R (2020) Variation of hydroxychloroquine blood levels in moroccan patients with systemic lupus erythematosus; a pilot study. Saudi J Med 05:6-10. https://doi.org/10.36348/ sjm.2020.v05i01.002

Petri M, Orbai AM, Alarcón GS, Gordon C, Merrill JT, Fortin PR, Bruce IN, Isenberg D, Wallace DJ, Nived O, Sturfelt G, RamseyGoldman R, Bae SC, Hanly JG, Sánchez-Guerrero J, Clarke A, Aranow C, Manzi S, Urowitz M, Gladman D, Kalunian K, Costner M, Werth VP, Zoma A, Bernatsky S, Ruiz-Irastorza G, Khamashta MA, Jacobsen S, Buyon JP, Maddison P, Dooley MA, van Vollenhoven RF, Ginzler E, Stoll T, Peschken C, Jorizzo JL, Callen JP, Lim SS, Fessler BJ, Inanc M, Kamen DL, Rahman A, Steinsson K, Franks AG Jr, Sigler L, Hameed S, Fang H, Pham N, Brey R, Weisman MH, McGwin G Jr, Magder LS (2012) Derivation and validation of the systemic lupus international collaborating clinics classification criteria for systemic lupus erythematosus. Arthritis Rheum 64(8):2677-2686. https://doi.org/10.1002/art.34473

Pons-Estel GJ, Alarcón GS, McGwin G Jr, Danila MI, Zhang J, Bastian HM, Reveille JD, Vilá LM (2009) Protective effect of hydroxychloroquine on renal damage in patients with lupus nephritis: LXV, data from a multiethnic US cohort. Arthritis Rheum 61(6):830-839. https://doi.org/10.1002/art.24538

Qu Y, Noe G, Breaud AR, Vidal M, Clarke WA, Zahr N, Dervieux T, Costedoat-Chalumeau N, Blanchet B (2015) Development and validation of a clinical HPLC method for the quantification of hydroxychloroquine and its metabolites in whole blood. Future Sci OA. https://doi.org/10.4155/fso.15.24

Réa-Neto Á, Bernardelli RS, Câmara BMD, Reese FB, Queiroga MVO, Oliveira MC (2021) An open-label randomized controlled trial evaluating the efficacy of chloroquine/hydroxychloroquine in severe COVID-19 patients. Sci Rep 11(1):9023. https://doi.org/10.1038/s41598-021-88509-9

Sames E, Paterson H, Li C (2016) Hydroxychloroquine-induced agranulocytosis in a patient with long-term rheumatoid arthritis. Eur J Rheumatol 3(2):91-92. https://doi.org/10.5152/eurjr heum. 2015.0028

Shapiro M, Levy Y (2017) The association between hydroxychloroquine treatment and cardiovascular morbidity among rheumatoid arthritis patients. Oncotarget 9(5):6615-6622. https://doi. org/10.18632/oncotarget. 23570

Shiboski CH, Shiboski SC, Seror R, Criswell LA, Labetoulle M, Lietman TM, Rasmussen A, Scofield H, Vitali C, Bowman SJ, Mariette X, International Sjögren's Syndrome Criteria Working G (2017) 2016 American college of rheumatology/european league against rheumatism classification criteria for primary Sjögren's syndrome: a consensus and data-driven methodology involving three international patient cohorts. Arthritis Rheumatol 69:35-45. https://doi.org/10.1002/art.39859

Song P, Li W, Xie J, Hou Y, You C (2020) Cytokine storm induced by SARS-CoV-2. Clin Chim Acta 509:280-287. https://doi.org/ 10.1016/j.cca.2020.06.017

Tang C, Godfrey T, Stawell R, Nikpour M (2012) Hydroxychloroquine in lupus: emerging evidence supporting multiple beneficial effects. Intern Med J 42(9):968-978. https://doi.org/10. 1111/j.1445-5994.2012.02886.x

Tang W, Khalili L, Giles J, Gartshteyn Y, Kapoor T, Guo C, Chen T, Theodore D, Askanase A (2021) The rise and fall of hydroxychloroquine with the covid-19 pandemic: narrative review of selected data. Rheumatol Ther 8(2):681-691. https://doi.org/ 10.1007/s40744-021-00315-x

Tishler M, Yaron I, Shirazi I, Yaron M (1999) Hydroxychloroquine treatment for primary Sjögren's syndrome: its effect on salivary and serum inflammatory markers. Ann Rheum Dis 58(4):253256. https://doi.org/10.1136/ard.58.4.253

van den Hoogen F, Khanna D, Fransen J, Johnson SR, Baron M, Tyndall A, Matucci-Cerinic M, Naden RP, Medsger TA Jr, Carreira PE, Riemekasten G, Clements PJ, Denton CP, Distler O, Allanore Y, Furst DE, Gabrielli A, Mayes MD, van Laar JM, Seibold JR, Czirjak L, Steen VD, Inanc M, Kowal-Bielecka O, Müller-Ladner U, Valentini G, Veale DJ, Vonk MC, Walker UA, Chung L, Collier DH, Ellen Csuka M, Fessler BJ, Guiducci S, Herrick A, Hsu VM, Jimenez S, Kahaleh B, Merkel PA, Sierakowski S, Silver RM, Simms RW, Varga J, Pope JE (2013) 2013 classification criteria for systemic sclerosis: an American college of rheumatology/European league against rheumatism collaborative initiative. Ann Rheum Dis 72(11):1747-1755. https:// doi.org/10.1136/annrheumdis-2013-204424

Wayne PA (2014) CLSI document C62-A Liquid ChromatographyMass Spectrometry Methods; Approved Guidelines. Clinical and Laboratory Standards Institute, Pennsylvania 
White NJ, Watson JA, Hoglund RM, Chan XHS, Cheah PY, Tarning J (2020) COVID-19 prevention and treatment: a critical analysis of chloroquine and hydroxychloroquine clinical pharmacology. PLoS Med 17(9):e1003252-e1003252. https://doi.org/10.1371/ journal.pmed.1003252

Worldometer (2021) Coronavirus. https://www.worldometers.info/ coronavirus/. Accessed 13 Sept 2021

Wu C-L, Chang C-C, Kor C-T, Yang T-H, Chiu P-F, Tarng D-C, Hsu C-C (2018) Hydroxychloroquine use and risk of CKD in patients with rheumatoid arthritis. Clin J Am Soc Nephrol CJASN 13(5):702-709. https://doi.org/10.2215/CJN.11781017

Wu CY, Tan M, Huang JY, Chiou JY, Wei JC (2020) Hydroxychloroquine is neutral in risk of chronic kidney disease in patients with systemic lupus erythematosus. Ann Rheum Dis. https://doi.org/ 10.1136/annrheumdis-2020-217728

Yap H-Y, Tee SZ-Y, Wong MM-T, Chow S-K, Peh S-C, Teow S-Y (2018) Pathogenic role of immune cells in rheumatoid arthritis: implications in clinical treatment and biomarker development. Cells 7(10):161. https://doi.org/10.3390/cells7100161

Publisher's Note Springer Nature remains neutral with regard to jurisdictional claims in published maps and institutional affiliations. 